\title{
Analysis on Related Policy of Midwest Area Rural-Urban Basic Education Teachers Migration
}

\author{
Qingyu Yang ${ }^{1, a}$ \\ ${ }^{1}$ Jiyuan Vocational and Technical College, Jiyuan, Henan, China, 459000
}

Keywords: Midwest Area, Teachers Migration, Report

\begin{abstract}
According to the national education policy development at all levels of government, "second five" attach great importance to promote the balanced development of urban and rural education, which is an important step to establish flow mechanism of urban and rural teachers, changing the drain rural schools teachers to strengthen rural basic Education faculty building. Based on the balanced development of education required, select Jiaozuo in Henan Province as a case, the relevant policies and measures to promote urban and rural teachers flow mechanism from the perspective of policy analysis on China's central and western regions investigated and analyzed, and how the Midwest according to local basic education the actual development, further improve the flow of urban and rural teachers on the basis of conditions and policies to protect some suggestions.
\end{abstract}

\section{Introduction}

From the "Twelve Five-Year", the state attaches great importance to the balanced development of urban and rural education, teacher resources and Manpower. Henan Province, central and western regions also actively respond to national policy, developed a number of policies aimed at promoting the flow of urban and rural teachers and seizes the opportunity to take a number of measures to promote the balanced development of education to a certain extent, but the problem cannot be ignored.

\section{The Policy Analysis of Midwest Promoting the Flow of Urban and Rural Teachers}

In order to promote the balanced development of urban and rural teachers, improve teacher flow mechanism of urban and rural, Henan Province, we formulated a series of policies according to the actual situation. In the "Teachers' Role in town" clearly states: Town Teacher Supporting Rural Education is an important measure to strengthen the building of rural teachers, promote the balanced development of urban and rural education; presented in "on strengthening the construction of rural school teachers views": rational allocation of resources, and vigorously promote the exchange of teachers, establishment of teacher exchange rotation system. From 2012 onwards, the progressive realization of urban teachers should be promoted to senior positions 1-- provision of rural education work experience 2 years. In order to encourage school teachers to traffic inconvenience, economic backwardness of the villages to teach, develop a remote, poverty-stricken areas and teachers of Allowance System mountainous village primary and secondary schools. Henan education development "Twelfth Five-Year Plan" further stated: Teachers should be reasonable two-way flow, establish and perfect the mechanism of complement rural teachers, rural and urban schools and the establishment of an effective mechanism for reasonable two-way flow between the strengths and weaknesses of the school teachers. According to these policies, Jiaozuo City, also made many provisions and adopted a series of initiatives.

Improve Primary and Secondary School Conditions and Adjust the Layout of the School. One of the city's reconstructions was construction and primary dangerous area decreased from 2001 to 12,125 square meters to 4985 square meters in 2007, at the end of 2015, the city's total of 352 schools has been transformed. Secondly, in the city, with intensive development as the goal, the primary and secondary schools into urban construction planning; in rural areas, the implementation of large-scale withdrawal point and the school, the school of scale. After transformation adjustment, the city's primary and secondary schools (primary and P in) 2001 to 1082 adjusted to 543 in 2014, 
180 people from the school are the number rose to 362. Teaching points from 2005 to 80 in 2014 reduced to 58, double classes also decreased from 2005 697-2014 140 years. In addition, new construction and expansion of the 48 boarding schools, to accelerate the implementation of education and information engineering, network of primary and secondary schools from 13 in 2001 to 89 in 2014.

By the Reform of Education Management System and Financial Investment System to Ensure Uniform Payment of Urban and Rural Teachers' Salaries. In 2006, Jiaozuo City, all counties (districts) reverted to the county teachers 'salaries tube, which would address the past teachers' salaries paid by the township level brought about by the time of issuance are not unified, standards are not unified, the treatment of imbalances. With the county teachers' salaries to co-ordinate further strengthen the macro-control functions of county government and the administrative department of education, teachers selected functions also promoted by the township (town) to a county level. This is beneficial for teachers overall co-ordination, so that the shortage of teachers in mountainous areas further eased. Moreover, in many parts of Jiaozuo, it has implemented urban and rural school teachers' health insurance, housing fund and other policies.

In Order to Realize the Rational Allocation of Teachers, it has the Introduction of Preferential Policies to Regulate the Imbalance of Urban and Rural Teachers Resources. As in "the city's Town Teacher Supporting Rural Education" provides that: During the teachers' wages and benefits to support education and human relations the original unit remains unchanged, length of service, seniority and job tenure teachers continuously calculated. Urban teachers and teaching and research staff to participate in various appraised grade teacher award, there must be more than 1 year teach in rural schools (teaching) experience or accumulated 480 hours of part-time rural schools teaching tasks. Another example is in Wenxian County, suburban and other places have issued a payment of teachers to remote mountain mountainous allowance and the provincial backbone teachers, subject leaders paid teacher allowance system. Through policy support and encouragement, so that a large number of young teachers to take root in the remote mountainous areas of school work. Xiuwu County took undergo full-time teaching, teaching part-time in the post, urban and rural two-way communication, science and technology to support education and other means to promote the rational allocation of teachers. Meanwhile, the trial also targeted recruitment hiring teachers approach has three open social recruitments of 320 college graduates to teach in rural areas, promote the development of rural education.

\section{The Problems of Urban and Rural Teacher Mobility in Midwest Area}

Driven by a series of policies and measures, Jiaozuo urban and rural teachers liquidity made certain achievements, effectively promoted the balanced distribution of teachers, but the issues involved and where there is obvious.

Management of Teachers Preparation is Inflexible, Hindering the Flow of Teachers In Urban and Rural Areas. Under the "county" based education management system, some of the financial difficulties of counties and cities in order to reduce the financial burden of teacher preparation and strict control. In urban areas, a retired teacher left, teacher preparation has not replenish, causing tension teacher preparation, for the protection of the completion of the task of teaching the school, the school is difficult to take a part-time teaching or teaching. As Xiuwu County elementary school students more than 3,000 people, according to the teacher-student ratio should be 167 full-time teachers, and the school only has 125 faculty members. The city of a junior high school, a total of nearly 1,000 students, according to student ratio should be 74 full-time teachers, and the current structure is only 57 full-time teachers, with teachers' sick leave, maternity leave, etc., there is a temporary substitute teachers this year 11. For the rural, since the teaching points scattered, small-scale schools, many teachers who is also the task of teaching several subjects, and if the teacher-student ratio is determined strictly according to teacher preparation, teaching cannot meet the demand, will result in the vast majority of rural schools appear teacher shortages. Therefore, even if some teachers want to school in the city or whether short-term exchange, because there is no other teachers with classes and lost opportunities. As Xiuwu County, a rural primary 
school, only 51 students, five grades, each grade a class, according to the teacher-student ratio of just three full-time teachers, and setting a quota is clearly unreasonable, schools should offer courses prescribed by the State, only hire temporary substitute teachers. According to the survey, rural counties in Jiaozuo-school district, 45 percent of full-time teacher, who is also the task of teaching several subjects, where many teachers are teaching classes package; $18 \%$ of the total number of teachers in hours per week more than 25 knots, maximum reach section 38. In the preparation of a certain number of tasks cannot be completed while the teaching situation, resulting in large numbers of substitute teachers. As only 3155 Xiuwu County teacher preparation and the annual need to hire 380 substitute teachers to meet the needs of teaching, substitute teachers and the cost cannot be paid financial funds. In the government "second five" introduced a series of policies to address the problem of private teachers and substitute teachers in rural schools, but the proportion of substitute teachers have been high, but mainly in rural primary schools. By the end of 2014, Jiaozuo municipal district substitute teachers for primary and secondary total of 765 people, including 503 rural primary schools there.

The Flow of Urban and Rural Teachers Lacks Practical System and Social Security and it is too Formalized. Although the city has developed urban teachers to support education rules and regulations, but it mostly promotes its encouragement and experimental, even though the development of relevant safeguards, but real implementation is not satisfactory. Due to the need to support education are generally more remote villages, during which will face difficulties in funding to support education, life, living, family and so on. Wenxian County as a high school, secondary school of their counterparts in the other support, remote location, it takes time to two hours, since the traffic inconvenience and recipient school teachers cannot solve the accommodation problem, teachers can only back and forth between school and home rushing. Furthermore, since the policy will support education and titles linked to many urban teachers to support education for promotion title, a last resort. Another condition is a combination of teaching and assessment, as some schools in the city, "Teacher elimination system", and after evaluation of teachers in the bottom to bring up the counties to rural schools in remote mountainous school "teaching", leading many teaching became the "face project", difficult to achieve the desired results. In order to improve the professional level of rural teachers, Yangquan formulated policies on rural teachers in urban schools attachment to learning, but in the implementation process is facing some problems. First, urban schools to rural teachers, their teaching does not give the opportunity, just lectures it, lest these teachers affect academic achievement and the quality of school education of students. Second, the flow would be mobilized. Rural teachers transferred to urban schools, liquidity gave them the opportunity to leave. In 2007, a high school town transferred 22 teachers, all transferred from the countryside, there are few teachers transferred from rural towns.

Withdrawal Point and Problems Left Are Not Resolved. Withdrawal point and the school is running in order to save costs and improve operating efficiency. However, with the implementation of this initiative, many problems follow. The first is the quality of education is affected, especially in urban schools, because the urban transformation, real estate development and transient student from the town led to a sharp increase in school enrollment, and because the school is in accordance with the criteria merge resident population base, resulting in serious school class sizes exceeded. Wen County as a high school students in more than 2,000 people, according to the standard set only 30 classes, the results of the first day, the second grade class size of about 70 people, and there are several third grade classes even more than 80 people, far It exceeded the national standard, seriously affecting the quality of education. Secondly, in the rural and mountainous areas, due to the withdrawal from the local primary school and teaching practical point of some inaccessible areas, withdrawal points and the school, students' families from the teaching point road farther, the school is unable to resolve the problem of student accommodation, very inconvenient to go to school resulting drop-out rate. Jiaozuo suburbs as a primary school, its students from the nearby seven villages in case the school does not provide accommodation, students are required to walk seven or eight kilometers per day. Wenxian County is located in the remote mountainous area, after some teaching points are removed and 7-8-year-old child would read to the township, in order to save 
time, the children left the mountain. Therefore, one can often see the mountain there is a day does not shine flashlight lighting. In such a difficult situation to go to school, some students drop out the idea of initiation, and some not so good student achievement is not intended to prevent early dropout parents under.

Aging Teachers, Subject Teachers Misallocation, Employment on Seniority and not the Ability, the Personnel System to be Improved. During the second five Jiaozuo City, he issued a series of preferential policies to attract college graduates to teach in rural schools, so that the proportion of young teachers in rural schools has increased. According to the survey, the city county area of rural primary school teachers under the age of 35 the proportion in 2001 from $16.2 \%$ in 2014 increased to $29.2 \%$, but the national average of $41 \%$ a far cry. And the phenomenon of aging teaching staff is serious, according to 2014 statistics, when the proportion of the city's rural primary school teachers over the age of 50 years are more than 35 teachers 3 percentage points. Another problem the team structure of rural teachers are subject teachers configuration of balance, especially the British, sound, beauty, computer and other disciplines teacher shortages. Because older teachers in large part by the positive private teachers, most of them through the normal school education get job training, they are not to the retirement age, no empty prepare teachers supplement the shortage of subjects, so that rural schools courses You cannot open a full blossom. The current staffing formulated according to the head only, without considering the structure of the balance of discipline, teachers learn to teach non-serious condition. Jiaozuo suburbs, for example, the region has a shortage of primary school English, computers, music, art, junior high school English, science and other subjects of more than 120 teachers. Many teachers' outskirts of a joint school with the successor academic teaching subjects do not meet professional counterparts to reach $46 \%$. Teachers' Professional Titles existing systems are not perfect, seniority is more prevalent in rural school teachers' titles usually determined by seniority and teachers work hard to mobilize the enthusiasm.

The Lack of Educational Facilities, Low Treatment of Rural Teachers, Compulsory Education Debt Problems to Be Solved. With the establishment of funds for compulsory education, "county-based" management system and guarantee mechanism, primary and secondary schools in rural school funding has been secured. But because the main responsibility for the school shifted owed when the original "three educational" debt burden to no one, no responsibility towns, schools cannot afford, no financial counties. These debts are very common, at least many tens of thousands of schools, as many as hundreds of thousands of millions. Jiaozuo suburbs rural schools more than 16 million in debt. Wenxian a high school education in recent years owed is unclear, as the first half of 2004, the school accumulated debts (mainly infrastructure investment) 530000. Xiuwu County Rural Schools in the county Xinhua Bookstore textbook only owe money amounted to 3.28 million. After the realization of free compulsory education system, the school funded entirely from funding. Since the levels of economic development constraints, the county district Jiaozuo City students of public funds is generally lower than the national average, rural primary and secondary school funding is very tight, more than $40 \%$ of total demand, a serious lack of funding for school equipment funding shortfall. Jiaozuo suburbs and teaching equipment such as compliance rate Xiuwu County rural schools is very low, the required equipment many rural school sports, health, art and teaching activities, the last century, the 1980s are equipped with the new curriculum is not complete, and the big part of old unusable. The Wenxian due to lack of school funding, rural teachers special subsidies cannot be achieved, School Headmaster allowance or execution of the 1980s Xingdingbiaozhun, only 2-15 RMB per month. In the central financial transfer payment funding, began in 2003 to implement the mountains and teacher subsidies, subsidies for teachers in remote mountain areas according to different levels of payment only 30-70 RMB. Teachers' Day 2003 began issuing the rural teachers of teacher allowances 60-100 RMB, these special allowance does not really solve the rural teachers' overall income is lower than the income of urban teachers' status quo. 


\section{Thinking of Improving the Flow Mechanism of Urban and Rural Teachers in the Central Region}

Jiaozuo City, Henan Province in the "five-second" Teachers Flow Mechanism in urban and rural areas, promote the balanced development of basic education in the process has made great success in Central and Western China also has a representative. In the realization of the "five" during the balanced development of basic education is a fundamental goal of China's educational development, and to achieve a balanced development of basic education, it must establish and improve the urban and rural teachers flow mechanism. Due to differences in the economic development of eastern and western and central regions of the basic conditions to achieve this goal it is very different, which must be based on the local economy, real social development, develop a realistic policy system and safeguards.

Rationally Adjust the Layout of Urban and Rural Schools, Increase Infrastructure of Rural Schools. First, we must rationally adjust the layout of rural schools through scientific planning. Adjustment of the layout of rural schools to the withdrawal of rural and town, immigration and village combination, but do not engage across the board, may be appropriate to retain some primary schools and teaching points in remote villages according to the actual situation; who are in the school-age population peak of the place to be in the "first construction, after merging" principle,

In principle, the implementation of layout adjustment, avoid school class sizes too large cause problems due to the layout adjustment. In particular, to strictly prevent the readjustment in the name of reducing investment in education, teaching resources and lead to conditions of full tension. Second, through the central and provincial fiscal transfer projects, increase investment in rural school infrastructure transformation, accelerate the pace of standardization of school. It suggested that the central and provincial to increase transfer payments to establish special funds to ensure the earmarking; to strengthen the reconstruction projects and continue to promote the construction and development of boarding primary schools, increase the intensity of boarding schools and equipment to ensure their school conditions; in accordance with the standardization of teaching equipment in rural schools, and educational information sharing hardware resources among regional and inter-school resources, to further promote the balanced development of urban and rural basic education.

The Establishment of Policy Orientation of Rational Flow of Teachers and Improve the Flow Mechanism of Urban and Rural Teachers. To make appropriate government guidance and market-driven combination of county government administrative intervention and strengthening co-ordination in the context of the flow of teacher autonomy, proper control of disorderly market liquidity teacher, teacher resources for the county overall arrangement and rational allocation. On the one hand to strengthen the weak school construction of teachers, the teachers stressed that the Government of the flow of administrative intervention, and improve policies and measures to support education of urban teachers to rural areas, protect the interests of teachers during flow, problem-solving transportation, accommodation and food and other aspects, initiative to support education teachers have substantial benefits and help. On the other hand city and county educational administrative departments should take effective measures to gradually narrow the gap between urban and rural teachers' welfare, protection of urban and rural teachers enjoy the same wage, housing, medical, pension and other benefits as soon as possible so that the different regions, different teachers actual income to maintain a balanced status. The amount of allowances rural teachers should have a certain strength, rather than embellishment, symbolic. Funds for central and western regions in rural remote areas difficult teachers special allowance system should primarily by the central and provincial financial burden, which should amount to at least $50 \%$ above the national average teacher. To expedite the development of teachers in rural areas to urban school attachment training system so that quality education resources sharing, so that teachers in rural areas can enjoy the demonstration school to enhance training opportunities to further enhance the level of business. Develop and improve the exchange of teachers in the assessment and evaluation system, rural teachers have to post teaching exercise clearly defined in terms of time, support policies must be implemented. Also regularly sends a group of full-time education of rural teachers 
annually through the normal students "internship" and other methods to improve the teaching ability of rural teachers.

Deepen the Reform of Teachers Personnel System, Improve Teacher Personnel Management System. Teachers in the county to achieve flow, requires teachers appointed by the county institutional educational administrative departments and schools to appoint teachers, county administrative department of education schools and teacher resources to control the region from the macro configuration. On the one hand it can modify the standard preparation of teachers, improve the preparation of standards in rural schools, especially in rural areas to increase the preparation of boarding school life, medical and other personnel. On the other hand allow older, less body, incapable of teaching and teachers in line with the relevant provisions for early undergo formalities, empty out the preparation, recruitment of qualified teachers of tertiary graduates to enrich teachers, promote the young teachers specialization. City and county levels of government can be set up in poor rural areas based "National Teachers special post" on the establishment of local "rural teachers special post" special funds to set up the necessary number of "supernumerary status" for rural primary and secondary schools, to resolve the current rural Since the preparation of school cannot be solved, only to employ the plight of substitute teachers. In the present case there is no preparation of teachers, can be combined with local conditions, the waiting list each year recruiting teachers to enrich the city's teachers, to be vacated after preparation by teachers who pass the examination replenish, so you can reserve young teachers, teachers to solve the problem of aging and achieve smooth transition of teachers and the replacement of old soft landing.

\section{Acknowledgements}

Fund Project: 2015 Annual Henan Science and Technology Agency Soft Science and Technology Projects (152400410394);

\section{References}

[1] Henan Education Department. Opinions on strengthening construction of rural school teachers. 2004. 3. 19

[2] Wang Ming. Education Development, Vol. 10 (2015) No 27, p.40-44

[3] Li La, Zhang Maocong. Educational Development Research, Vol. 30 (2004) No 19, p.144-145

[4] Lou Shizhou. Educational Science Research, Vol. 29 (2008) No 27, p.21-23

[5] Zhang Gongxu, Sun Jing. Educational Development Research, Vol. 8 (2003) No 27, p.57-60 